\title{
PODCASTS COMO UM DESIGN ALTERNATIVO PARA O ENSINO DE PORTUGUÊS PARA REFUGIADOS NO BRASIL
}

\section{PODCASTS AS AN ALTERNATIVE DESIGN FOR TEACHING PORTUGUESE TO REFUGEES IN BRAZIL}

\author{
Ana Carolina Fontana de Oliveira ${ }^{1}$ \\ Vinicius Villani Abrantes ${ }^{2}$
}

\begin{abstract}
RESUMO
Esta pesquisa está inserida no contexto das migrações internacionais forçadas - cenário, no qual, o Brasil figura-se como um dos receptores (Estado de destino) de inúmeros refugiados. É fato que, na última década, o Brasil se deparou com um crescimento representativo no fluxo migratório em seu território - o que levou diversos programas e projetos a se adaptarem para esse contexto, auxiliando no processo de integração e o acolhimento dos refugiados. Atrelado a diversas dificuldades, uma das maiores barreiras dentro desse processo é sem dúvidas a língua. Nessa ambiência, o objetivo geral do presente artigo é o estudo do contexto de acolhimento e integração linguística de refugiados no Brasil; torna-se objetivo específico, apontar as contribuições dos podcasts no ensino e aprendizado de português, levando em consideração a diferença constitutiva e objetiva das salas de aula de Português como Língua de Acolhimento. Dentro desse cenário, no entanto, frisa-se que a língua que acolhe, por diversas vezes pode silenciar, dificultando, assim, que os refugiados possam territorializar naquele espaço físico e simbólico portanto, o presente artigo encontra-se na perspectiva do ensino daqueles alunos que desejam aprender a língua portuguesa brasileira, sem que haja imposição de novos códigos de linguagem e cultura. Nessa linha de raciocínio, a partir da transdisciplinaridade, este trabalho se encontra na demanda de novas construções identitárias inerentes aos movimentos contemporâneos, se justificando pelo potencial em corroborar para que profissionais, possam ter novas perspectivas para conduzirem futuros enfrentamentos da temática em território nacional. Para tal, realiza-se uma revisão bibliográfica em textos especializados, legislações e protocolos internacionais e nacionais.
\end{abstract}

\footnotetext{
${ }^{1}$ Mestranda em Linguística, pela Faculdade de Letras, da Universidade Federal de Juiz de Fora (PPG Linguística/FALE/UFJF). Graduada em Letras, com ênfase na Língua Inglesa, pela Faculdade de Letras, da Universidade Federal de Juiz de Fora (FALE/UFJF). E-mail: ana.fontana@letras.ufjf.br. ORCID: <https://orcid.org/0000-0001-7886-8035. Lattes: http://lattes.cnpq.br/0714226072518632.

2 Graduando em Letras, pela Faculdade de Letras, da Universidade Federal de Juiz de Fora (FALE/UFJF). Graduando em Direito, pela Faculdade de Direito, do Instituto Metodista Granbery (FMG). Pesquisador no Grupo de Estudos e Pesquisa em Direito Internacional, no projeto de pesquisa: "Direito Internacional Crítico" (GEPDI/DICRÍ/CNPq/UFU). Pesquisador no Portal Direito Internacional sem Fronteiras, no projeto de pesquisa: "Os Direitos da Criança no Sistema Internacional”. E-mail: mlvillaniabr@gmail.com. ORCID: https://orcid.org/0000-0003-38502834. Lattes: http://lattes.cnpq.br/384813160936432.
} 
Palavras-chave: Ensino de Língua. Português como Língua de Acolhimento. Direitos Humanos. Linguística Aplicada. Transdisciplinaridade.

\begin{abstract}
This research is inserted in the context of forced international migrations - a scenario in which Brazil appears as one of the recipients (destination state) of countless refugees. It is a fact that, in the last decade, Brazil has faced a representative growth in the migratory flow in its territory - which has led several programs and projects to adapt to this context, helping in the integration process and the reception of refugees. Linked to several difficulties, one of the greatest barriers within this process is undoubtedly the language. In this context, the general objective of this article is to study the context of the reception and linguistic integration of refugees in Brazil; it becomes a specific objective to point out the contributions of podcasts in the teaching and learning of Portuguese, taking into consideration the constitutive and objective difference in the classrooms of Portuguese as a Host Language. Within this scenario, however, it is emphasized that the language that hosts several times can silence, thus making it difficult for refugees to territorialize in that physical and symbolic space - therefore, this article is in the perspective of teaching those students who wish to learn the Brazilian Portuguese language, without imposing new codes of language and culture. In this line of reasoning, from transdisciplinarity, this work is in demand of new indenitary constructions inherent to contemporary movements, justified by the potential to corroborate so that professionals can have new perspectives to conduct future confrontations of the theme in national territory. To this end, a bibliographical review is carried out in specialized texts, legislation and international and national protocols.
\end{abstract}

Keywords: Language Teaching. Portuguese as a Host Language. Human Rights. Applied Linguistics. Transdisciplinarity.

As fronteiras separam o nós do eles, interrompem, circunscrevem ou produzem segregações na distribuição de populações ou de atividades dentro das sociedades. Essas fronteiras não são dadas, constroem-se, ultrapassam-se e desconstroem-se no tempo e com o tempo. Enquanto algumas já antigas são frequentemente estabilizadas, outras, mais recentes, podem ser mais flexíveis e são mais questionadas. Entretanto, as fronteiras mais antigas também podem ser abolidas. Enfim, todo processo definidor de fronteiras sociais é o desfecho das lutas e rebeldias pela classificação social (classement) e contra a desclassificação (déclassement) ${ }^{l}$.

\title{
INTRODUÇÃO: Uma Pesquisa em Constante Movimento
}

Migrar é um direito humano, entretanto, sabe-se que com o passar das décadas e das novas perspectivas da globalização, consequentemente, mudanças também ocorreram nas mobilidades humanas ${ }^{2}$. Santos (2001) aponta que principalmente as faces perversas da globalização geram grandes interferências nos processos migratórios - isto é, surgimento de

\footnotetext{
${ }^{1}$ IOKOI, Z. M. G. Fronteiras em movimento: deslocamentos e outras dimensões do vivido. Revista Diversitas, vol. 1, n. 1, p. 12 .

${ }^{2}$ A título de conhecimento, sabe-se que a "construção do Brasil é marcada por diversas ondas de imigrações que ajudaram na composição da sociedade em aspectos culturais, étnicos, sociais e econômicos. Cada um desses fluxos presenciados correspondeu a eventos e situações específicas dentro do plano nacional e internacional neste ponto, fazendo um paralelo com a esfera jurídica, é possível perceber que cada um desses momentos "de diásporas" fizera com que a jurisdição necessitasse de matérias diferenciando os sujeitos de acordo com sua situação migratória" (ABRANTES, 2020, p. 83).
} 
novas doenças ou até mesmo o retorno de doenças que já estavam praticamente erradicadas, queda da taxa de crianças e adolescentes inseridos no sistema educacional, entre outros.

Ao chegarem no Estado de destino, os refugiados necessitam do novo idioma para se comunicarem - fato que mostra que a língua é uma necessidade indispensável para o grupo (CABETE, 2010; AMADO, 2013; LOPEZ, 2016; ABRANTES; ROMERO, 2020), ainda mais em países que não possuem diretrizes consolidadas para um humano e efetivo acolhimento linguístico daqueles refugiados. É relevante mencionar que as políticas linguísticas de acolhimento a refugiados não devem apenas se pautarem na construção e efetivação, no caso brasileiro, do Português (como Língua de Acolhimento), uma vez que o grupo de refugiados não deve ser obrigado a aprender o idioma do Estado em que se encontra, abandonando códigos culturais e linguísticos maternos - isto, se construiria uma violação grave de direitos humanos ${ }^{3}$.

Neste cenário de recebimento de refugiados pelo Estado brasileiro, o voluntário desejo e, por vezes, a necessidade, de aprender o idioma de destino, a presente pesquisa busca responder como os podcasts, muito em voga nos dias atuais, podem se tornar uma das opções para o ensino de português para refugiados. O objetivo geral desse artigo é o estudo do contexto de acolhimento e integração linguística de refugiados no Brasil; torna-se objetivo específico, apontar as contribuições dos podcasts no ensino e aprendizado de português, levando em consideração a diferença constitutiva e objetiva das salas de aula de Português como Língua de Acolhimento.

A temática "migrações", atualmente, pertence ao rol de assuntos mais abordados e pesquisados, entretanto, ainda são poucas as pesquisas que se debruçam a estudar tal eixo temático por um viés transdisciplinar - ou nas palavras de Truzzi e Monsma (2018, p. 18), "por tradições disciplinares distintas". Nessa ambiência, o estudo de natureza qualitativa,

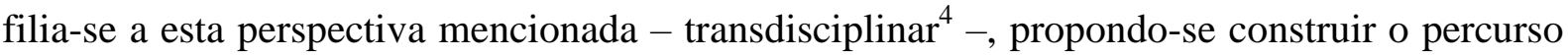
crítico da obra, por meio da incorporação de textos especializados das áreas do direito, da linguística aplicada, da psicologia e da educação.

\footnotetext{
3 A língua que acolhe, por diversas vezes pode silenciar, dificultando, assim, que os refugiados possam territorializar naquele espaço físico e simbólico.

${ }^{4}$ A transdisciplinaridade como elemento constitutivo das pesquisas em Linguística (Aplicada) já tem sido pauta de diversas discussões, tais como Moita Lopes (2008); Signori e Cavalcanti (2004). Os referidos autores, nesta toada, apresentam tal conexão como um elemento metodológico crítico, comprometido com questões sociais, políticas, éticas, entre outras - em prol da construção de uma noção progressista da linguagem. Isto porque, de fato, compreender que a língua é uma prática social envolta de questões ideológicas, sociais e políticas. Nas palavras de Leffa (2001, p. 4-5 apud SCHEIFER, 2013), "pesquisar em LA [Linguística Aplicada] é como pesquisar petróleo no mar: precisamos abandonar o conforto de caminhar em terra firme, com balizas enterradas no chão, e aprender a navegar, assestando nossos instrumentos em plataformas móveis". A transdisciplinaridade permite a construção do conhecimento científico articulada com a lógica territorial, da qual o território é constituído por lugares contíguos, lugares em cadeira e controle de fluxos e conexões (HAESBAERT, 2009 apud SCHEIFER, 2013).
} 
Para uma melhor sistematização do manuscrito, apresenta-se na primeira seção de discussão um panorama sobre os refugiados no Brasil, para que em outra toada, na segunda seção de debate, seja apresentada sobre o surgimento dos podcasts e a viabilidade deles para o ensino de idiomas. Logo em seguida, é apontado perspectivas sobre Português como Língua de Acolhimento.

\section{O Brasil como receptor de refugiados}

A cartilha do ACNUR (2020, p. 10) define, com base na legislação nacional e internacional vigente, são aqueles que "estão em uma situação de risco e vulnerabilidade, pois não têm proteção de seus respectivos países e sofrem ameaças e perseguições”. Enquanto, os migrantes seriam os que "optaram por viver no exterior principalmente por motivações econômicas ou educacionais, podendo voltar com segurança ao seu país de origem se assim desejar" (ACNUR, 2020, p. 10). É importante mencionar que tais definições também se encontram firmadas em documentos internacionais que versam sobre direitos humanos e migrações - tais como: a Declaração Universal de Direitos Humanos (1948); Convenção de Genebra (1951) e protocolo adicional (1966).

Em território nacional, com a promulgação da Constituição da República de 1988, uma nova visão sobre o "migrante" passa a figurar - deixa-se de vinculá-los como ameaças nacionais, e os colocam como sujeitos também dignos de proteção nacional. Nessa perspectiva, em 2017, com a Nova Lei de Migração - Lei 13.445/2017 e o respectivo decreto regulamentador (n. . 9.199/2017), o Brasil é, de fato, colocado em um novo patamar em matéria de direitos humanos e direito do migrante - "a lei supracitada trata o imigrante como um sujeito de direitos, reafirmando a Constituição Federal de 1988 (especialmente o artigo $5^{\circ}$ ), garantindo a condição de igualdade entre os nacionais e os não-nacionais" (ABRANTES, ROMERO, 2020, p. 271-272).

Em uma perspectiva global, o relatório emitido pelo GIFE (2020) aponta que atualmente há mais de 270 milhões de migrantes internacionais, sendo que mais de 70 milhões são deslocamentos forçados - o relatório aponta que dos deslocamentos forçados, mais de 40 milhões são deslocados dentro das fronteiras internas do país. Além disso, o supracitado relatório aponta ainda que existem mais de 26 milhões em situação de refúgio em todo o mundo; frente a este cenário, a GIFE (2020) apresenta que no Brasil existem cerca de 
807 mil pessoas imigrantes $-0,4 \%$ da população total ${ }^{5}$-, seriam 32.565 indivíduos com o status de refugiado reconhecidos pelo Brasil.

O relatório ainda menciona alguns desafios envolvidos ao contexto dos refugiados em território nacional: ausência de uma Política Migratória e de Refúgio Nacional, bem como de dispositivos e parâmetros orientadores para a integração local; insuficiência de políticas estaduais e municipais para migrantes e refugiados, havendo poucas experiências exitosas no país; dificuldade no acesso a informações sobre processos, direitos e serviços; falta de conhecimento no idioma do país de destino, criando obstáculos para a comunicação, sociabilidade e inserção profissional (GIFE, 2020), entre outros.

É evidente que todos os desafios apresentados anteriormente, de certa maneira, vão ao encontro do que permeia o contexto desta pesquisa - o desconhecimento da língua de destino. É neste ponto que se pode observar que "a língua é vista como uma forma de concessão à cidadania” (ABRANTES; ROMERO, 2020, p. 272) - é válido mencionar que não apenas uma cidadania legal, mas também a simbólica (aquela que permitirá o sentimento de pertencimento ao território) (ABRANTES; ROMERO, 2020).

Assim sendo, é evidente que o Português como Língua de Acolhimento (PLAc) é uma das pautas que deve ser debatida nas agendas nacionais voltadas ao acolhimento de refugiados - na próxima seção será apresentado algumas considerações sobre o PLAc, bem como seus respectivos pilares ${ }^{6}$.

\section{Português como língua de acolhimento}

O ensino de Português como Língua de Acolhimento, em território brasileiro, apresenta um crescente movimento, nos últimos anos. A partir da criação dos cursos de Português como Língua Estrangeira, em diversas Instituições, muitos desses cursos começaram a receber migrantes transnacionais, dessa maneira, diversos desses programas e projetos necessitaram passar por adaptações estruturais e metodológicas.

Esse fato aponta o trabalho constante realizado pelos institutos, principalmente no que tange a pesquisas na área. Calha apontar, neste contexto, que o desenvolvimento dos projetos

\footnotetext{
${ }^{5}$ De acordo com o estudo desenvolvido pelo Instituto IPSOS (em 2018), o Brasil é o quarto país do ranking com visões equivocadas sobre à percentagem de habitantes imigrantes em território nacional - o estudo aponta que se acredita que o grupo corresponda a $30 \%$ da população nacional.

${ }^{6}$ Até o fechamento desta pesquisa nenhum documento oficial brasileiro sobre migrações e refúgio traçou diretrizes e programas de Português como Língua de Acolhimento - a maior parte das iniciativas advém dos Institutos de Ensino Superior públicos e privados, com parceria com outros setores da sociedade civil, tais como: a Cátedra Sérgio Vieira de Mello. Vide: ABRANTES, V. V; ROMERO, T. G. Vozes Silenciadas das Migrações de Crise no Brasil: "para que língua de acolhimento?". E-civitas: Rev. Cient. do Curs. de Dir. do UNIBH, vol. 13, núm. 2, 2020, p. 275-281.
} 
e programas não estão ligados diretrizes nacionais ou internacionais: são iniciativas específicas de professores, departamentos específicos e organizações.

O ensino de Português como Língua de Acolhimento, de acordo com Grosso (2010), vai além da noção de língua adicional ou segunda língua. Isto porque as crescentes trocas linguísticas e os diferentes contextos de ensino, promovem novas formas de se ver a educação e as perspectivas do futuro - o ensino de língua se insere em questões de reconstrução e remodelação da ideia de uma sociedade mais justa, acolhedora e intercultural.

O Brasil desenvolveu grandes mudanças, nas últimas legislações, com relação ao refugiado, porém, ainda está aquém de ter políticas públicas linguísticas institucionalizadas inclusive, diretrizes e parâmetros, para os próprios programas de Português como Língua de Acolhimento (AMADO, 2013). O Ministério das Relações Exteriores lança em 2020 uma coleção de cartilhas sobre propostas curriculares para o ensino de português em diversas unidades, entretanto, nenhuma delas ainda inicia ou apresenta parâmetro para o contexto específico de Português como Língua de Acolhimento.

Neste contexto, a título comparativo, a carta social europeia, ratificada pelos EstadosMembros do Conselho da Europa, prevê o dever do Estado em proporcionar e facilitar o ensino do idioma nacional, em parâmetros de Língua de Acolhimento, para todos os migrantes. A carta mostra a importância da língua, no processo de integração (FONTANA; ABRANTES; ROMERO, 2020).

A língua possui grande importância no processo de territorialização, dessa maneira, políticas e diretrizes acerca da problemática devem constar em pautas de políticas sociais das diversas esferas de um Estado. Vale dizer que as políticas linguísticas voltadas para o acolhimento devem colocar a língua como um pressuposto, no qual o migrante transnacional possa estar, de maneira ativa, na sociedade em que está inserido. Em outras palavras, a construção das políticas linguísticas deve ser encarada como um processo que facilite com que o grupo de migrantes possa criar agentividade, diminuindo as vulnerabilidades.

\section{Pilares para projetos de português como língua de acolhimento}

O ensino da Língua Portuguesa brasileira, no contexto das migrações, deve seguir alguns parâmetros importantes. Isto para que atenda, de forma humana, os alunos que necessitam adquirir habilidades neste idioma ${ }^{7}$.

\footnotetext{
${ }^{7}$ De acordo com Fontana, Abrantes e Romero (2020), o ensino da língua-alvo (ou língua de destino) deve ser estruturado (e acompanhado) de traços de sensibilidade. É extremamente importante apontar que a sensibilidade mencionada, deve ser profissional e pessoal - a primeira, relacionada a sensibilidade de uma formação em direitos humanos e cultural, pautada em valores de uma cidadania global; enquanto, a segunda, estaria relacionada na capacidade do profissional em articular a gestão do ambiente de ensino.
} 
É extremamente relevante que os profissionais que ministram esses cursos tenham formação específica na área - a formação de professores para atuarem em Português como Língua de Acolhimento deve conter conhecimentos de direito humanos, culturais e de competência cultural $^{8}-$, haja vista que o papel do professor, nesses casos, é construir e contribuir com instrumentos linguísticos para que os migrantes transnacionais possam ativamente trilhar histórias. É uma tarefa de reumanização, dessa maneira, é necessário ter sensibilidade nas práticas de integração por meio da língua e linguagem.

Em adição ao mencionado anteriormente, se torna um pilar importante também, a prática. Entre as práticas do Português como Língua Estrangeira e o Português como Língua de Acolhimento existe uma grande diferença cultural e ideológica marcada por um contexto de violações e refúgio. Na prática de Português como Língua de Acolhimento, alguns desafios podem ser elencados (MIRANDA; LOPES, 2019), dentre eles, por exemplo, a falta de materiais didáticos específico ${ }^{9}$. O professor não adquire todas as respostas dentro da formação teórica, portanto, é relevante que além da base teórica, o profissional também possua uma formação prática destina ao contexto (FONTANA; ABRANTES; ROMERO, 2020).

Para além disso, se mostra necessário, o desenvolvimento de trabalhos coletivos, isto é, de constantes e progressivos diálogos entre os profissionais de Português como Língua de Acolhimento com diferentes interlocutores que atuam no referido contexto (FONTANA, ABRANTES \& ROMERO, 2020), para que assim possa contribuir, para o que Miranda e Lopez (2019) apontam como uma reflexividade crítica sobre suas práticas, possibilitando novas perspectivas sobre o contexto e ensino.

\section{Podcast no ensino}

O podcast surgiu em 2004, quando Adam Curry e Daver Winer emitiram um programa de rádio via web (RICHARDSON, 2006), ganhando a partir desse momento uma popularidade pela sua facilidade em criar e em publicar materiais digitais. O dicionário online Priberam ${ }^{10}$ define podcast como um:

Ficheiro áudio ou multimédia, divulgado com periodicidade regular e com conteúdo semelhante ao de um programa de rádio, que pode ser descarregado da Internet e lido no computador ou em dispositivo próprio (PRIBERAM, 2020, online).

\footnotetext{
${ }^{8}$ É uma competência internacionalista de conseguir conectar os diferentes pontos de vista através de dilemas e reconciliações.

${ }^{9}$ Cada turma especifica possui necessidades específicas - isto depende do tempo de vivência no país de acolhimento, do nível de conhecimento prévio sobre a língua e a cultura, dos objetivos e dificuldades do aluno para com a língua, suas nacionalidades, e entre outras características.

10 Dicionário da Língua Portuguesa. Lisboa: Priberam Informática, 1998. Disponível em: <http:www.priberam.pt/dlDLPO>. Acesso: 17 de janeiro de 2021.
} 
O termo podcast é um acrônimo das palavras public on demand (pod) e broadcast (cast), podendo, dessa forma, ser descrito de forma resumida como sendo uma emissão pública segundo uma demanda específica (RICHARDSON, 2006). O podcast assemelha-se a uma inscrição em uma revista em áudio, no qual podemos ter acesso através da internet. As suas temáticas podem ser diversos, desde curiosidades até conteúdo acadêmico, podendo ser acessado a partir de programas específicos que leem ou transmitem os arquivos de podcast.

Segundo Leite $(2016 ; 2018)$, atualmente, há três formatos desse gênero, eles são: (I) o podcast de áudio, (II) o podcast aprimorado, e (III) o podcast de vídeos. O primeiro, que contêm apenas áudio, é chamado de audiocast (MCLOUGHLIN; LEE, 2007; WEEB; CAVANAGH, 2008 apud LEITE, 2018) - é um dos tipos mais utilizados na educação, no qual as loções podem ser gravadas, auxiliando aqueles que não puderam participar do momento presencial em sala de aula e contribuir para que os estudantes revejam as lições para complementar as suas anotações. O segundo, o podcast aprimorador, possui informações de multimídia que ajudam os usuários a aumentar sua percepção sobre o tópico. Por fim, o podcast de vídeos, também conhecido como videocast (LEITE; LEÃO; ANDRADE, 2010), foi a última forma de podcast a ser inventada no mundo, trocando os áudios presentes no podcast tradicional por vídeos.

O podcast, principalmente o de áudio, possui características interessantes para serem utilizados no ensino de línguas, pois, além de permitir a introdução de temas contextualizados, motivando assim as discussões de temas da disciplina ou até mesmo da atualidade, também auxilia na consolidação da matéria ministrada em sala de aula. O aluno pode ouvir esses áudios pelo dispositivo móvel (celular), enquanto está indo para o trabalho ou até mesmo quando estiver fazendo algum exercício físico, maximizando, nessa perspectiva, as horas de aprendizagem.

Nessa seara, é válido mencionar que como em qualquer tecnologia - educacional ou adaptada a educação -, o uso do podcast produz uma alta interatividade com o usuário, proporcionando uma grande experiência na aprendizagem, visando ajudar tanto o educador como os alunos a alcançarem os objetivos propostos em sala de aula (LEITE, 2018). Contudo, como é detalhado por Leite (2018) que para a utilização dessa plataforma, como tantas outras que estão surgindo na contemporaneidade, deve-se ter um conhecimento básico e domínio dessa plataforma pelo professor e pelos alunos.

Considerando Freire (1971), a educação é uma prática de leitura de mundo, não há como separar a sala de aula e a vida social. Na perspectiva mencionada, tal ferramenta possibilita a veiculação de temas relevantes aos estudantes, mas que são muitas vezes 
excluídos das discussões em sala de aula ${ }^{11}$. Desse modo, o acesso e, futuramente, uma possível produção de podcasts pelos alunos migrantes, permite (e permitirá) a liberdade de expressão dos alunos, corroborando para sua formação cidadã.

Moura e Carvalho (2006) ao defenderem o podcast como uma ferramenta de partilha intercultural, corroboram para o enfrentamento das desigualdades do poder e da hierarquização sociocultural - isto porque, quebram com a perspectiva colonial ${ }^{12}$ de fontes muito restritivas do conhecimento, bem como da dominação por meio da língua. Os podcasts auxiliaram em uma reforma da educação dos povos, permitindo um ensino crítico que possibilite práticas e códigos linguísticos e culturais hegemônicos.

De acordo com Rojo (2018), deve-se notar que a multiplicidade de culturas são "produções letradas em efetiva circulação social, como um conjunto de textos híbridos de diferentes letramentos, de diferentes campos, desde sempre caracterizados por um processo de escolha pessoal e política e de hibridização de produções de diferentes "coleções"” (ROJO, 2012, p. 13). Com isso, deve-se ter consciência que o podcast que será indicado para os alunos acarretará questões e debates além do conteúdo de sala de aula. Nesses áudios, que serão indicados para os alunos, serão apresentados uma multiplicidade de linguagens, culturas e questões sociais que, se o professor não ficar atento, pode escapar a oportunidade de apresentar uma estão importantes para a adaptação sociocultural e linguística desse aluno.

A utilização dos podcasts em sala de aula apresentam questões muito importantes do multiletramento que são a interatividade e o colaboracionismo do que está sendo apresentado com o aluno; o podcast fratura e transgride as relações de poder estabelecidas em sala de aula, em especial as relações de propriedade, principalmente pela questão de troca de informações e culturas que podem acontecer em sala simplesmente com a exposição de um único áudio, transformando todos em professores e alunos; e por ser uma ferramenta hibrida, fronteiriça e mestiça na questão linguagens, modos, mídias e culturas, muito característico do aluno do qual estará em sala com o professor. Dessa forma, um podcast pode ser apresentado para um aluno migrante e utilizado não só na sala de aula, mas também na vida social e adaptação cultural desse aluno, pois está mais próximo da vivência que ele vai ter fora de sala.

\section{Considerações finais: entre conquistas e desafios}

\footnotetext{
${ }^{11}$ Conforme foi apontado na seção de discussão anterior, o ensino de Português para refugiados se difere do ensino para alunos conveniados de Instituições de Ensino parceiras ou que optaram voluntariamente pela aprendizagem da Língua Portuguesa brasileira.

${ }_{12}$ "As relações de colonialidade atravessam as diferentes esferas sociais, e tem como principal elemento o controle do poder. Essas relações de poder se dão em escalas diferentes, como por exemplo, em relação a força do trabalho, em relação ao gênero e ao sexo. A colonialidade tem sobrevivido e tomado novas formas nas sociedades pós-modernas e desconstruir o pensamento colonial é, ainda hoje, um desafio" (VASCONCELOS; LOPES, 2019, p. 1-2).
} 
O uso de podcast no ensino de Língua Estrangeira no Brasil ainda é uma perspectiva recente - que vem sendo mais intensificada, principalmente, perante as transformações sociais e tecnológicas na educação, impulsionadas pela pandemia de COVID-19. Portanto, acreditaseque o uso de podcasts pode colaborar com o processo de ensino e aprendizagem da Língua Portuguesa brasileira, tornando a sala de aula de PLAc um espaço de aprendizado significativo, que vise não apenas o aprendizado de conteúdos, mas também um local de desenvolvimento dos estudantes como indivíduos - em sua integralidade. Isto significa que a sala poderá se tornar uma atmosfera capaz de guiar e de construir uma educação crítica, criativa e cidadã aos refugiados.

Acrescenta-se ainda que os podcast - sejam eles utilizados como uma ferramenta em sala de aula ou como auxiliar externo - possibilitará o melhor aproveitamento do tempo dos estudantes, maximizando a exposição desses a conteúdos vocabulares e culturais do cotidiano - consequentemente, corroborando para a consolidação da agentividade do sujeito (ABRANTES, ROMERO, 2020) como conhecedores da sociedade na qual estão vivendo (BARROS; MENTA, 2007).

Certamente, faz-se uma constante consolidação dos direitos humanos em todos os seus níveis, principalmente, na construção de uma educação mais digna e humana - que possa assegurar mecanismos emancipatórios para os refugiados atuem como amplos atores sociais.

Por fim, sublinha-se que este é um eixo de pesquisa desta investigação que requer maior estudo, entretanto, conforme mencionado anteriormente, é possível observar a importância dos podcasts como ferramenta que possibilitará o contato com a língua e os códigos culturais do país; isto é, uma ferramenta para a adaptação cultural e linguística de alunos de PLAc (FREIRE, 2013) - incluindo, aqui, então, a possibilidade dos estudantes refugiados terem os podcast como um grande auxílio para o desenvolvimento da oralidade (BARROS; MENTA, 2007).

\section{Referências}

ABRANTES, V. V; ROMERO, T. G. Vozes Silenciadas das Migrações de Crise no Brasil: "para que língua de acolhimento?". E-civitas: Rev. Cient. do Curs. de Dir. do UNIBH, Vol. 13, núm. 2020. 2, Disponível em: https://revistas.unibh.br/dcjpg/article/view/3010/pdf67890 >. Acesso em: 17 de janeiro de 2021.

ABRANTES, V. V. A necessidade de políticas públicas linguísticas para a construção da agentividade do migrante no Brasil. In: OLIVEIRA, S. A. A. de; UCHOA, S. A. de O.; DIAS, F. P. da S.; SILVA, H. M. de L. (Org.). Línguas, Tecnologia, Inclusão e Ensino: caminhos que se entrecruzam. Cajazeiras: Inst. Desen. Educ. Interd. e Aprendizagem, 2020, p. 82-94. 
AMADO, R. de S. O ensino de português como língua de acolhimento para refugiado. Revista Siple, vol. 4, núm. 2, 2013. Disponível em: http://www.siple.org.br/index.php?option=com_content\&view=article\&id=309:o-ensino-deportugues-como-lingua-de-acolhimento-para-refugiados\&catid=70:edicao-7\&Itemid=113.

Acesso em: 17 de janeiro de 2021.

BARROS, G. C.; MENTA, E. Podcast: produções de áudio para educação de forma crítica, criativa e cidadã. Revista Eletrônica Internacional de Economia Política da Informação, da Comunicação e da Cultura, vol. 9, n. 1, 2007. Disponível em: https://seer.ufs.br/index.php/eptic/article/view/217. Acesso em: 17 de janeiro de 2021.

BENEDETTI, Janaína Lupatini. As Potencialidades do Uso de Podcast no Ensino de Língua Portuguesa. 2018. 44 f. TCC (Graduação) - Curso de Curso de Especialização em Mídias na Educação, Universidade Federal do Rio Grande do Sul, Porto Alegre, 2018.

CABETE, M. A.C. S. S. O processo de ensino-aprendizagem do português enquanto língua de acolhimento. 2010. 120 p. Dissertação (Mestrado em Língua e Cultura Portuguesa) - Universidade de Lisboa, Lisboa, 2010.

FONTANA, A. C. de O.; ABRANTES, V. V.; ROMERO, T. G. O papel do português como língua de acolhimento nas políticas públicas de integração de migrantes de crise: uma visão jurídico-linguística. In: SILVA, R. C. da; ABRANTES, V. V. (org.). Reflexões iniciais sobre direito internacional. Curitiba: Brazil Publishing, 2020. p. 1-240.

FREIRE, E. P. A. Aplicações escolares do Podcast. In: Congresso Nacional de Ambientes Hipermídia para aprendizagem, 2013, João Pessoa. Disponível em: http://wright.ava.ufsc.br/ alice/conahpa/anais/2013/assets/aplicacoes_escolares_eugeni.

Acesso em: 20 de janeiro de 2021.

FREIRE, P. Conscientização: Teoria e prática da libertação: Uma introdução ao pensamento de Paulo Freire. $3^{\text {a }}$ ed.; São Paulo: Centauro, 2006.

GIFE - Grupo de Institutos Fundações e Empresas. Migrações e Refugiados: Um guia para investidores sociais privados e organizações filantrópicas, GIFE, 2020. Disponível em: https://www.empresascomrefugiados.com.br/materiais-de-referencia. Acesso em: 01 de novembro de 2020.

GROSSO, M. J. dos R. Língua de acolhimento, língua de integração. Horizontes de Linguística Aplicada, vol. 9, núm. 2, p. 61-77, 2010. Disponível em: < https://periodicos.unb.br/index.php/horizontesla/article/view/886 >. Acesso em: 20 de janeiro de 2021.

IOKOI, Z. M. G. Fronteiras em movimento: deslocamentos e outras dimensões do vivido. Revista Diversitas, vol. 1, n. 1, p. 12. Disponível em: http://diversitas.fflch.usp.br/revistadiversitas-0. Acesso em: 17 de janeiro de 2021.

LEITE, Q. dos S. S. Podcasts no processo de ensino e aprendizagem da língua portuguesa: o trabalho com a variação linguística na era digital. 2018. 125 f. Dissertação (Mestrado) - Curso de Programa de Pósgraduação em Formação de Professores, Universidade Estadual da Paraíba, Podcasts no Processo de Ensino e Aprendizagem da Língua Portuguesa: O Trabalho Com A Variação Linguística na Era Digital, 2018. Disponível em: http://posgraduacao.uepb.edu.br/ppgfp/download/Dissertacao-Quesia-dos-Santos-Souza-Leite-PPGFP2018.pdf. Acesso em: 17 de janeiro de 2021. 
LEMOS, A. Podcast: emissão sonora, futuro do rádio e cibercultura. Disponível em: http://saladeaulainterativa.pro.br/moodle/mod/book/view.php?id=2274. Acesso em: $17 \mathrm{de}$ janeiro de 2021.

LOPEZ, A. P. de A. Subsídios para o planejamento de cursos de português como língua de acolhimento para imigrantes deslocados forçados no Brasil. 2017. 260 p. Dissertação (Mestrado) - Universidade Federal de Minas Gerais, Belo Horizonte, 2016.

MIRANDA, Y. C. C.; LOPEZ, A. P. A. Considerações sobre a formação de professores no contexto de ensino de português como língua de acolhimento. In: Ferreira, L. C. et al. (org.). Língua de acolhimento: experiências no Brasil e no mundo. Belo Horizonte: Mosaico Produção Editorial, 2019. p. 17-40.

MOITA LOPES, L. P. (Org.). Por uma Linguística Aplicada indisciplinar. São Paulo: Parábola, 2008.

MOURA, A; CARVAlHO, A. A. A. Podcast: Potencialidades na Educação. Revista Prisma, vol., núm. 3. p.88-110, 2006. Disponível em: http://ubicomp.algoritmi.uminho.pt/csmu/proc/147.pdf. Acesso em: 17 de janeiro de 2021.

ROJO, R.; MOURA, E. (orgs). Multiletramentos na escola. São Paulo: Parábola. 2012.

SANTOS, M. Por uma outra globalização. Rio de Janeiro: Record, 2001.

SCHEIFER, C. L. Transdisciplinaridade na linguística aplicada: um processo de desreterritorialização - um movimento do terceiro espaço. Rev. bras. linguist. apl., vol. 13, núm. 3, p. 919-939, 2013. Disponível em: https://www.scielo.br/pdf/rbla/v13n3/aop2013.pdf. Acesso em: 17 de janeiro de 2021.

SIGNORINI, I. Do residual ao múltiplo e ao complexo: o objeto da pesquisa em Linguística Aplicada. In: SIGNORINI, I.; CAVALCANTI, M. C. (Org.). Linguística aplicada e transdisciplinaridade: questões e perspectivas. Campinas: Mercado de Letras, 2004. p. 99-110.

TRUZZI, O.; MONSMA, K. Sociologia das migrações: entre a compreensão do passado e os desafios do presente. Sociologias, Porto Alegre, vol. 20, n. 49, 2018, p. 18-23.

VASCONCELOS, V. F. S.; LOPES, C. R. (De)colonialidade no Ensino/Aprendizagem de Línguas. Anais da XV ENFOPLE: UEG, 2019. Disponível em: < https://www.anais.ueg.br/index.php/enfople/article/view/13728 >. Acesso em: 17 de janeiro de 2021.

Artigo recebido em: 02/02/2021. Artigo aceito em: 28/02/2021. 